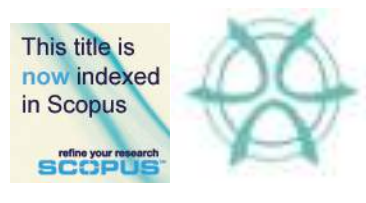

PLANNING MALAYSIA:

Journal of the Malaysian Institute of Planners

SPECIAL ISSUE IV (2016), Page 17 - 30

\title{
MANAGING URBANISATION AND URBAN SPRAWL IN MALAYSIA BY USING REMOTE SENSING AND GIS APPLICATIONS
}

\author{
Nur Aulia Rosni ${ }^{1}$, Norzailawati Mohd Noor $^{2} \&$ Alias Abdullah ${ }^{3}$ \\ 1,2,3 Kulliyyah of Architecture \& Environmental Design \\ INTERNATIONAL ISLAMIC UNIVERSITY MALAYSIA
}

\begin{abstract}
In the global era, more than half of the world population live in urban area. With rapid urbanisation growth where the highest percentage concentrates in Asia, a relevant approach is needed to eliminate the possible threat that occurs after urbanisation took place; the urban sprawl. Urban sprawl is a popular term in academic discourse and has a long history but until these days, the concrete definition of this term is not yet configured. Many studies of sprawl have rooted back in non-Asian countries making the solution for sprawl is not suitable to be implemented in term of theories and practice. This research attempts to study the measurement of sprawl by using these geospatial indexes with Remote Sensing and GIS approach. The SPOT-5 images with 2.5 meters resolution were used to analyse the growth of sprawl in Kuala Lumpur metropolitan due to its high urbanisation rate. The findings show that Kuala Lumpur is a sprawling city. It is anticipated that this research will provide a new direction in urban sprawl studies and represent a robust analytic approach for characterizing urban development on the city scale at once as well as promoting a city via Remote Sensing and GIS technology.
\end{abstract}

Keyword: Urban Sprawl Measurement; Geospatial Indices; Urbanisation; Remote Sensing; GIS; Asian Cities

\section{INTRODUCTION}

Urbanisation can be defined as the physical growth of urban areas as a result of global change when people move into the city from the rural area. Urbanisation is closely linked with modernisation, industrialisation, and the sociological process of rationalisation. According to Bhatta et al. (2010), urbanisation is a process of population concentration; the shift from a rural to an urban society, and involve an increase in the number of people in urban areas during a particular year. Economic and social development cause urban concentration and expansion of large cities using changes in land use pattern as well as the transformation of organisation and governance from rural to metropolitan.

Bhatta et al. (2010) have made a clear statement to distinguish between Urban Growth and Urbanisation, which both are claimed as the main process of urban development. Urban development is a process where an area is growing due to the increasing demand in cities and urban value. Urban growth were referred as a spatial and demographic process that denotes the significance of towns and cities as a concentration 
Nur Aulia Rosni, Norzailawati Mohd Noor \& Alias Abdullah

Managing Urbanisation and Urban Sprawl in Malaysia by Using Remote Sensing and GIS Applications

of population within a particular economy and society while Urbanisation is a spatial and social process that refers to the changes of behaviour and social relationships that occur in social dimensions as a result of people living in towns and cities.

Jaafar (2004) has stated that urbanisation or growth of urban areas are phenomena that increase the concern of policy makers and town planners since the trend of urbanisation have wide-ranging implications for socio-economic development. Traditionally, urbanisation has a strong connection with industrialisation process. The development of industrial activities usually focused in the urban area due to the availability of infrastructure and facilities; this scenario created more job opportunities that cause many people chose to migrate to the urban area. The high number of the population requires more source of energy to be provided in order to enhance human productivity that leads increasing demand for both industry and agriculture. This situation will cause the rapid and massive growth of migration to large cities. Urbanisation can result in positive and negative consequences. In most urbanised countries, some of the issues are employment, sanitation, housing, sewage, water, fire, social welfare, the role of government, and political machines.

Due to urbanisation, the housing and infrastructure cost also increase due to the scarcity of resources such as land area, water and building materials. Moreover, the major environmental impact of large cities often includes traffic congestions and noise pollution. Urbanisation process causes the city to decay which the local authority cannot provide service that meet the need of the residents. Air pollution resulted from overdependence on motorised transport, and water pollution resulted from poor sewage facilities. Based on the different views and opinion on the Urban development, Urban Growth and Urbanisation, it can be concluded that these process will affect three main aspects which are (1) Physical, (2) Demographic and (3) Social factors in an area which all of this aspect closely linked to urban sprawl.

Urban sprawl is a stage that takes place after urbanisation. Cities grow vertically and achieve certain density tend to continue to grow horizontally, spilling out from its border and infecting the outside area around the original town. It is one of the low-density developments which mean it occupies the lot of space that functioned as natural habitat, vacant land or even farmland. Urban sprawl and its impacts have attracted increasing attention from planners and policy makers resulting in heated discussions on its definition, measurement, causes and negative consequences. A selection of urban sprawl definitions has been derived to describe sprawl and as a particular form of urban development with low density, disperse, auto-dependent, environmentally and socially-impacting characteristic (Burchell and Shad 1998; Ewing 2002; Galster et al 2001; Majid et al 2010). Urban sprawl is a process that is characterized by an unforeseen and jagged pattern of growth, driven by a multitude of processes and leading to inefficient resource utilisation (Bhatta et al. 2010). Uncontrolled, unplanned and uncoordinated growth of urban areas causes the urban sprawl to occur. Urban sprawl which is both inefficient and unsustainable is due to the inability of town planners, policy makers and the authority to visualize such growth during planning, policies and decision-making process.

The methods to measure urban sprawl have been a hot issue for research. Many scholars tend to focus on using indicators to measure urban sprawl by establishing multidimensional indicators by GIS analysis or descriptive statistical analysis (Galster et al., 2001). Sprawl can be measured in relative and absolute scales (Bhatta et al., 2010). 


\begin{abstract}
Absolute measurements are capable of creating a black and white distinction between a sprawled city and compact city. GIS and remote sensing can be combined or used separately in studying urban sprawl, both applications can supply physical, social and economic data for simulation Mohd Noor et al. (2009). There are some researchers on how to use remote sensing and GIS to monitor and measure urban sprawl (Sudhira \& Ramachandra, 2007; Weng, 2001; Yeh \& Li, 1999). Remote sensing has the capability to provide spatially consistent datasets that cover vast areas with both high spatial detail and high temporal frequency. It has been in use since 1960; remote sensing can also provide consistent historical time series data. Remote sensing is a "unique view" of the spatial and temporal dynamics of the processes of urban growth and land use change (Herold, Menz, \& Clarke, 2001). Satellite remote sensing techniques have, therefore, been widely used in detecting and monitoring land cover change at various scales with a useful result (Wilson et al. 2003). Recently, remote sensing has been used in combination with Geographical Information System (GIS) and Global Positioning System (GPS) to assess land cover change more effectively than remote sensing data alone (Weng, 2001). The combination of GIS and remote sensing are useful in mapping urban areas, and as data source for the analysis and modelling urban growth, and land use/land cover change (Herold, Goldstein, \& Clarke, 2003; Wilson et al., 2003).

According to Majid (2011), as different types of sprawl are caused by various factors, different approaches are required to address them. Advocating for more compact development in order to address sprawl phenomenon in Malaysian cities, for example, may not necessarily work without first knowing the type of sprawl the cities are facing. Many approaches have been used to quantify the sprawl, and one of the methods has been suggested by Heargreaves (2014) in his article which concludes main components in calculating a sprawl was the density of houses and jobs. Ewing et al. (2014) have stated that there have been numerous applications of the original sprawl index. The original sprawl index was made available to researchers who wished to explore the various costs and benefits of sprawl. The county sprawl index operationalized only two dimensions of urban form residential density and street accessibility. These measures are modelled after a complete metropolitan sprawl indices developed by Ewing et al. (2002). The refined indices operationalize four dimensions, thereby characterizing county sprawl in all its complexity. The four are development density, land use mix, population and employment cantering, and street accessibility. In this paper, the best way to measure urban sprawl is by using five of the land use pattern spatial factors. The spatial factors include Leapfrog Development, Discontinuous Development, Segregated Land-Use Development, Planning Consistency Index, and Urban Density Development. The calculation was carried out based on GIS and remote sensing application, and the results of the analysis were visualized as maps. Based on the calculated results, the researchers were able to identify an empirical metric for distinguishing between urban sprawl from non-sprawl urban development.
\end{abstract}


Nur Aulia Rosni, Norzailawati Mohd Noor \& Alias Abdullah

Managing Urbanisation and Urban Sprawl in Malaysia by Using Remote Sensing and GIS Applications

\section{OBJECTIVE}

The research was conducted to measure urban sprawl development in Kuala Lumpur city by applying the geospatial indicators developed in the western countries in the local geographical development background. It is to investigate as well the relationship and influence of urbanisation process and urban sprawl. The process involved literature review on the urban growth, urbanisation and urban sprawl, the issues and problems as well as the impact. This research is the pioneer to further develop a geospatial measure that suite the local background and at the same time contribute to the knowledge and defining sprawl.

\section{STUDY AREA}

In 2010, the Asia-Pacific region's urban population were 754 million people which is more than the population of the United States of America combined with the European Union. The urbanisation rate in South East Asia has been increased over the years and expected to achieve 50million people in 2020 as compared to only 30 million people in 1990. However, urbanisation growth in Asia is regarded as environmentally unsustainable with the growth of slums in overpopulated urban areas, a high level of social and economic inequality (ESCAP 2010). Urbanisation in Malaysia can be classified into three major period starting with the founding of urban areas during colonisation period in the 1800 s, followed by urban growth, development and increasing urbanisation in the early years of independence (1950s). The urbanisation rate in Malaysia is increasing year by year from about $25 \%$ in 1960 to $65 \%$ in 2005 . Malaysia target to achieve $70 \%$ urbanisation rate in the year 2020 which means $70 \%$ of its total population are living in the urban area.

The majority of the urban population enjoy a high standard of living with good access to clean water and sanitation facilities. The Tenth Malaysia Plan focuses on developing infrastructure to improve productivity and making the private sector as the engine of development. The plan identifies 12 National Key Economic Area, which Kuala Lumpur, the largest urban centre in Malaysia is one of it. Kuala Lumpur Metropolitan $\left(3^{\circ} 8^{\prime} 51^{\prime \prime} \mathrm{N} 101^{\circ} 41^{\prime} 36^{\prime \prime} \mathrm{E}\right)$, which covers an administrative area spread over 24,221.05 hectares (figure 1). Majority of the land use patterns consist of built-up areas (residential, industrial, commercial, institution, recreation area, road, infrastructure, and utilities) and unbuilt areas (agriculture, forest, bare land, and water bodies). The population of Kuala Lumpur was 1,600,000 in 2012 (Kuala Lumpur Local Plan, 2010-2015). To achieve better future urban development and infrastructure planning, it is crucial for the Kuala Lumpur City Hall to recognize sprawl phenomenon happening in Kuala Lumpur including on how to measure and determine urban sprawl factors and patterns in order to control its growth. 

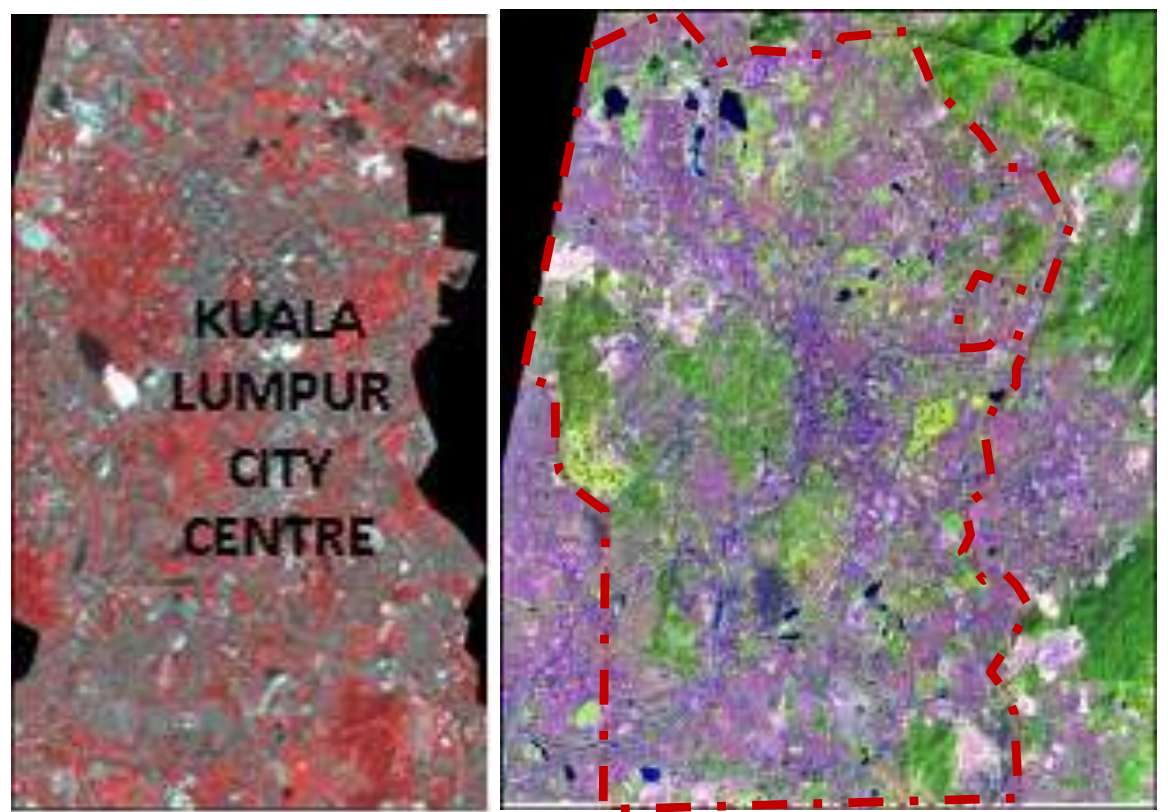

Figure 1: Location of study area - Kuala Lumpur District, Malaysia

\section{SOFTWARE AND MATERIALS}

Extensive availability of remote sensing images, spatial data and geospatial tools has seen some surge in the intensity of urban sprawl studies. A typical urban sprawl study involves an attempt at quantifying the amount of paved surface and built up area in a given region using remotely sensed data or other geospatial data. The coverage of these paved and built up areas will then be used to identify the pattern and extent of urban sprawl. In other words, urban sprawl mapping can help in picturing how and where the growth of a city is occurring. These situations allow the responsible authority to recognize types of development that can be executed or need to be avoided in the particular area. Moreover, threatened natural and environmental resources can be identified and preserve which likely support future development that is not only sustainable but also help to reduce urban sprawl. By analysing the urban sprawl growth pattern in an area over a period, its nature and characteristic can be indulged and managed by the responsible authority primarily the local planning authority.

Moreover, Yeh and Xia (1999) have stated that GIS and remote sensing are very useful tools especially in the formulation and implementation of temporal and spatial changes. The changes in spatial and temporal development are an essential component in planning practice particularly for monitoring purposes in order to ensure sustainable development. The different stages in the elaboration and implementation of a regional development strategy can be generalized to determination of objectives, resource inventory, analysis of the existing situation, modeling and projection, development of planning options, selection of planning options, plan implementation, and plan evaluation, monitoring and feedback (Yeh and Xia, 1999). GIS and remote sensing techniques are quite developed and operational to implement such a proposed strategy. 
Nur Aulia Rosni, Norzailawati Mohd Noor \& Alias Abdullah

Managing Urbanisation and Urban Sprawl in Malaysia by Using Remote Sensing and GIS Applications

These applications are now also providing new tools for advanced ecosystem management. The collection of remotely sensed data facilitates the synoptic analysis of earth's system function patterning and change at local, regional and global scales.

According to Agarwal (2007), the real world cannot solely be represented in two dimensions as is commonly accepted. Most modelling in GIS has been two dimensional especially in the context of urban planning. The development in the field of "fuzzy logic" and "artificial neural networks" is providing the option of incorporating indeterminate and ambiguous information from the real world into GIS. This will be especially helpful while considering the cognitive models and individual perception of people and incorporating them by reference into GIS. For this study, the primary research mainly depended on the data obtained from MACRES, Department of Survey and Mapping Malaysia (JUPEM), and the local authority (Kuala Lumpur City Council). The satellite data were the primary sources while the ancillary data were the secondary data (Table 1). The satellite data included SPOT-5 images from 2012. On the other hand, the ancillary data consisted of topographic maps, land use maps, road map, contour line, and urban map. The software used to calculate and analyse the raw data and to generate the results included ERDAS, ArcGIS, MapInfo, E - cognition and SPSS.

Table 1: Data sources for study

\begin{tabular}{lc}
\hline Type of Data & Year of Acquisition/Publication \\
\hline Spot-5 images (2.5 meter) & 2012 \\
Topographic Maps & 2010 \\
Land Use Maps & 2010 \\
Road Map & 2010 \\
Contour Line & 2010 \\
Urban Map & 2010 \\
Vector Data & 2010 \\
\hline
\end{tabular}

The spatial patterns of urban sprawl on the temporal scale are studied and analysed using the satellite imageries and cadastral data from related agencies as previously mentioned. The data then being mapped, monitored and accurately assessed from satellite data along with conventional ground data. The image processing techniques are also quite effective in identifying the urban growth pattern from the spatial and temporal data captured by the remote sensing technologies. This method will help in demarcating the pattern of urban sprawl growth in a city. In this research, the pattern of urban sprawl growth will be based on the selected land use factor of geospatial indices. Mapping urban sprawl contributes to identifying areas where environmental, and natural resources are critically threatened and to suggest likely future directions and patterns of sprawling growth. Herold et al. (2001) has support the statement by proving that the models have shown potential to help planning and management decisions by providing knowledge and understanding of the dynamics of the urban system (intuition structuring), anticipating and forecasting future changes or trends of development, describing and assessing impacts of future development, and exploration of different policies and optimisation of urban planning and management. Urban sprawl mapping and monitoring is one of the operational applications of satellite remote sensing data, irrespective of its spatial and 
spectral resolution of the satellite-borne sensors. Later, the result of GIS and remote sensing usage in urban sprawl studies will be explained further in the next sections.

\section{METHODS}

The image pre-processing and data preparation were carried out; these included image rectification and mosaicking. The image-to-map procedures were applied to the Spot 5 images using set of ground control point's area that appeared in the same place, both in the imagery and known locations in corresponding map and urban plan used as ancillary information in the rectification process. The rectified datasets were then mosaicked thus producing the entire study area from Vector Data images as supported data (Figure 2). Image classification was then applied to the pre-processed image and the land use classes map of the entire study area was produced. Supervised classifications techniques were chosen for this study, which was performed using the object-based classifier in ECognition software system. The system enabled all fine details of the land cover to be classified and later merged accordingly to form the classes in accordance with urban land use classes used in urban planning practice. In this study, the object-based classifier was employed to build optimal training areas and to build up knowledge for each category of interest prior to the classification of the entire image. Initially, the algorithm trained the spectral classes by supervising the training process after collecting the parametric and non-parametric signatures (training samples). After completion of the training process, the entire knowledge of the class's occurrence within the SPOT-5 image was generated. The knowledge was then used to identify all the pixels in the picture into the trained classes with multi-resolution segmentation approach. The classes identified were then recategorized into two main classes namely unbuilt and built up, apart from identifying them further into detailed of the type of 11 land uses.

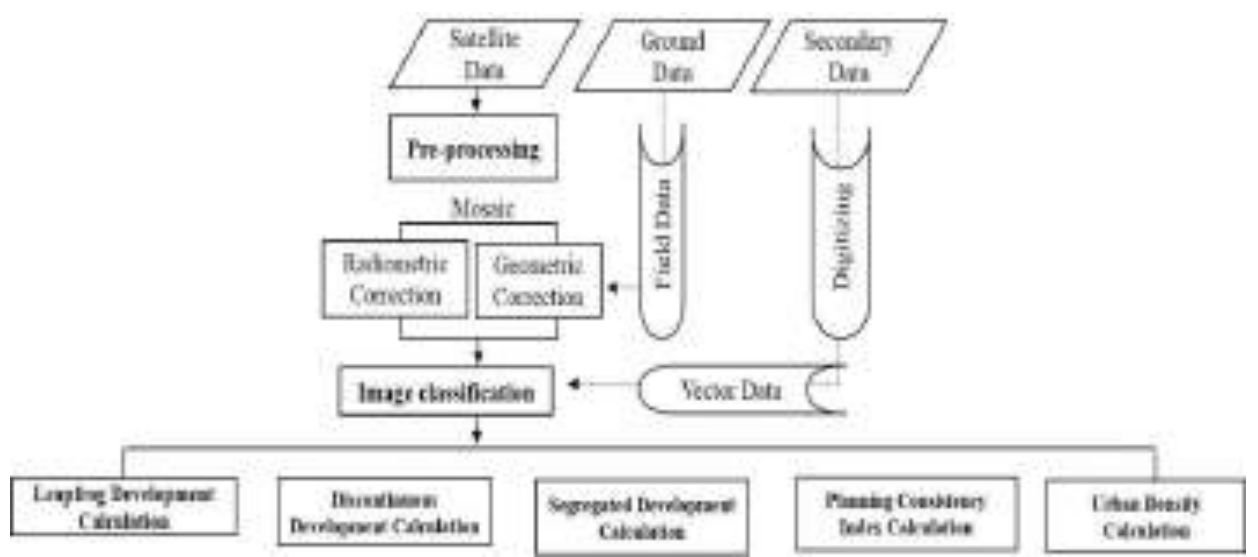

Figure 2: Flowchart of data processing adopted in the study

The sets of SPOT-5 images were successfully geometrically corrected with transformed RSO coordinate with RMSE \pm 0.5 pixels to ensure the accuracy of the sprawl. In fact, this RMSE has been widely used as a good practice to ensure good geometric output apart from ensuring the sound configuration of ground control point that is evenly 
Nur Aulia Rosni, Norzailawati Mohd Noor \& Alias Abdullah

Managing Urbanisation and Urban Sprawl in Malaysia by Using Remote Sensing and GIS Applications

distributed in the study area. Fill this imagery is also subject to image enhancement. The image classification was carried out in two steps process to produce first level classes of built and unbuilt areas and further detailed land use classes within the built-up areas. Final classified image classes are as tabulated in Table 2.

Table 2: Land use classified for year 2010

\begin{tabular}{llcc}
\hline & Land Use Class & Area (ha) & Percent (\%) \\
\hline 1. & Residential & $5,489.56$ & 22.66 \\
2. & Commercial & $1,091.71$ & 4.51 \\
3. & Industrial & 553.05 & 2.28 \\
4. & Institution & $1,620.80$ & 6.69 \\
5. & Infrastructure And Utilities & $5,029.62$ & 20.77 \\
6. & Open Area And Recreation & $1,579.56$ & 6.52 \\
7. & Community Facilities & $1,382.44$ & 5.71 \\
8. & Undeveloped land & $5,756.74$ & 23.77 \\
9. & Squatters & 570.63 & 2.36 \\
10. & Utilities & $1,146.94$ & 4.73 \\
\hline
\end{tabular}




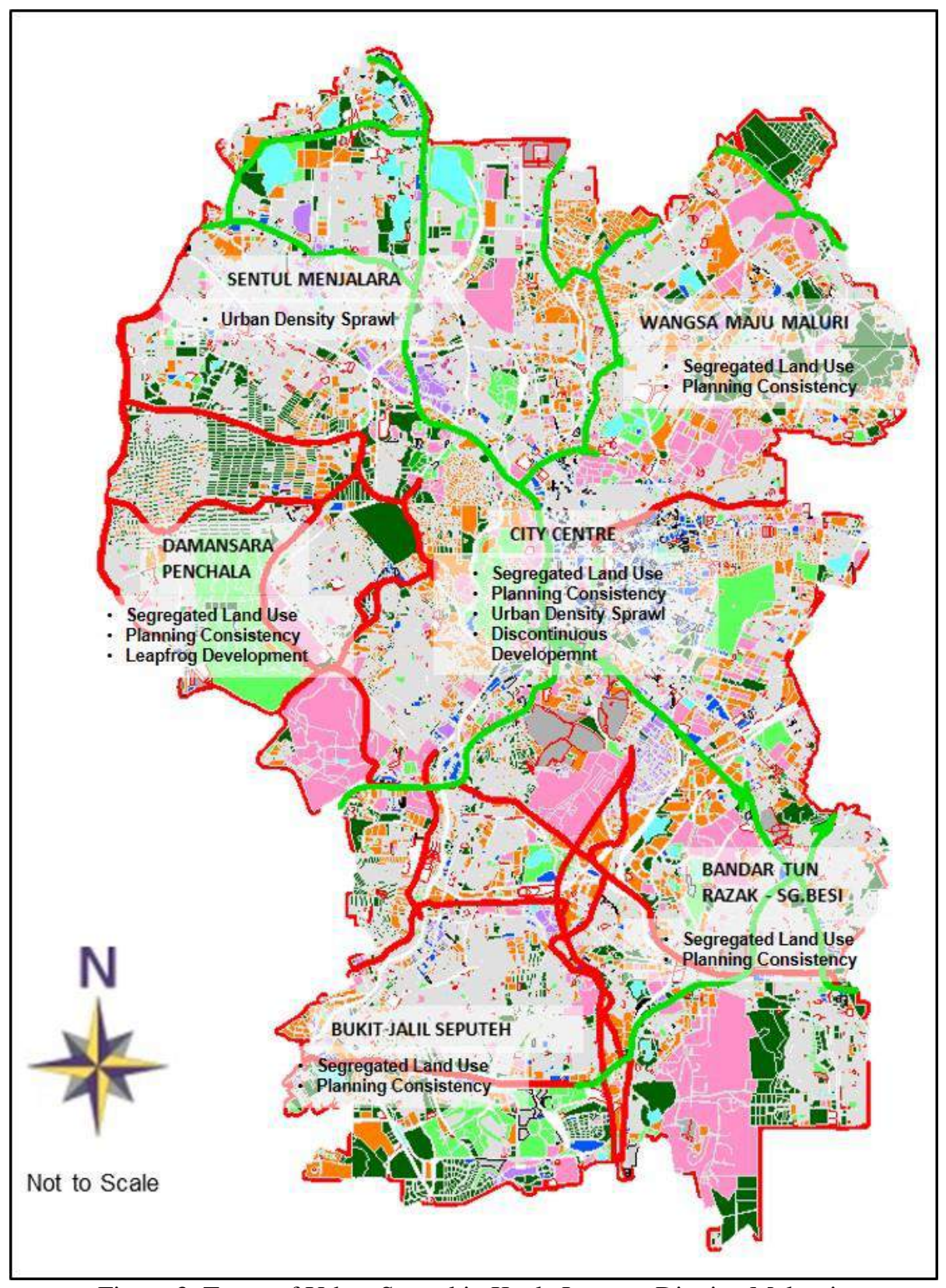

Figure 3: Types of Urban Sprawl in Kuala Lumpur District, Malaysia 
Nur Aulia Rosni, Norzailawati Mohd Noor \& Alias Abdullah

Managing Urbanisation and Urban Sprawl in Malaysia by Using Remote Sensing and GIS Applications

Based on the geospatial indices of urban sprawl measurement that have been conducted, the results show that all areas in Kuala Lumpur are facing different types of sprawl problems (Figure 3). The city centre has the most types of sprawl which are segregated land use, urban density sprawl, planning consistency, and discontinuous development. The next city with a high number of urban sprawl types is DamansaraPenchala district which have three types of urban sprawl namely planning consistency, leapfrog development and segregated land use. However, only one type of geospatial indices urban sprawl that are occurring in Sentul Menjalara district. The remaining three district (Wangsa Maju- Maluri, Bdr. Tun Razak - Sg. Besi and Bukit Jalil- Seputeh) has two types of urban sprawl for each district. The majority of the areas in Kuala Lumpur have less than three types of land uses. This situation indicates that Kuala Lumpur is facing urban sprawl but not in the critical level. However, without proper measures to overcome the current problem, the future development of Kuala Lumpur might lead to bigger sprawl growth. The urbanisation process in Kuala Lumpur started at the City Centre due to mining activities in the 1850s. The mining town was developed organically which means that no proper city planning have been implemented along with its urbanisation process. Then the urbanisation process has spread to the neighbouring area from the city centre to Damansara - Penchala and Wangsa Maju- Maluri. People tend to move from high-density area to suburban area due to spacious residential land and low cost of residential building as compared to the city centre. Many of the workers from middle-income group choose to commute from their residential area in suburban to work in the city to save cost on housing.

However, previous studies in urban sprawl demonstrate the true costs of sprawl, and attempt to show that if new development was built at higher densities and with proper public transit, lots of money could be saved as compared to developing new land area near the urban area. The new development outside the urban area has its hidden costs, identifying innovations note that there is demand for sprawl, for the suburban home and that, even though, the infrastructure and operating costs are considerably higher, the price is often cheaper. But with new development, facilities like road network need to be built to cater the need of suburban settlers. Roads are free to use but aren't cheap to build or maintain. The cost of building roads come from the taxpayers. Plus, the provision of too many roads for private vehicles has caused traffic congestion and pollution in Kuala Lumpur.

Abdullah (2012) has stated that the trend of urban sprawl has continued unabated in major metropolitans of Malaysia especially Kuala Lumpur, whereby most of the new developments are located in the periphery. These developments have implications for socio-economic developments and cultural aspects of cities in Malaysia. His study shows that the movement of sprawl development in Kuala Lumpur is moving towards the fringe area of Kuala Lumpur, which is in line with the findings as shown in figure 3. Figure 4 summarized the findings based on three different scores according to spatial indices by using the new residential area as a point of reference. Based on the results, it can be sure that there are many areas in Kuala Lumpur is facing sprawl. Kuala Lumpur, previously was an administrative centre has change to function only for capital city and as commercial centres after the seat of government was shift to Putrajaya in 1999 in order to reduce congestion and overcrowding of Kuala Lumpur (Kuala Lumpur City Plan 2020). However, the urban sprawl phenomenon still occurs in the city where development 
highly takes place. The urban sprawl that took place in Kuala Lumpur is different in each district and based on the different characteristic.

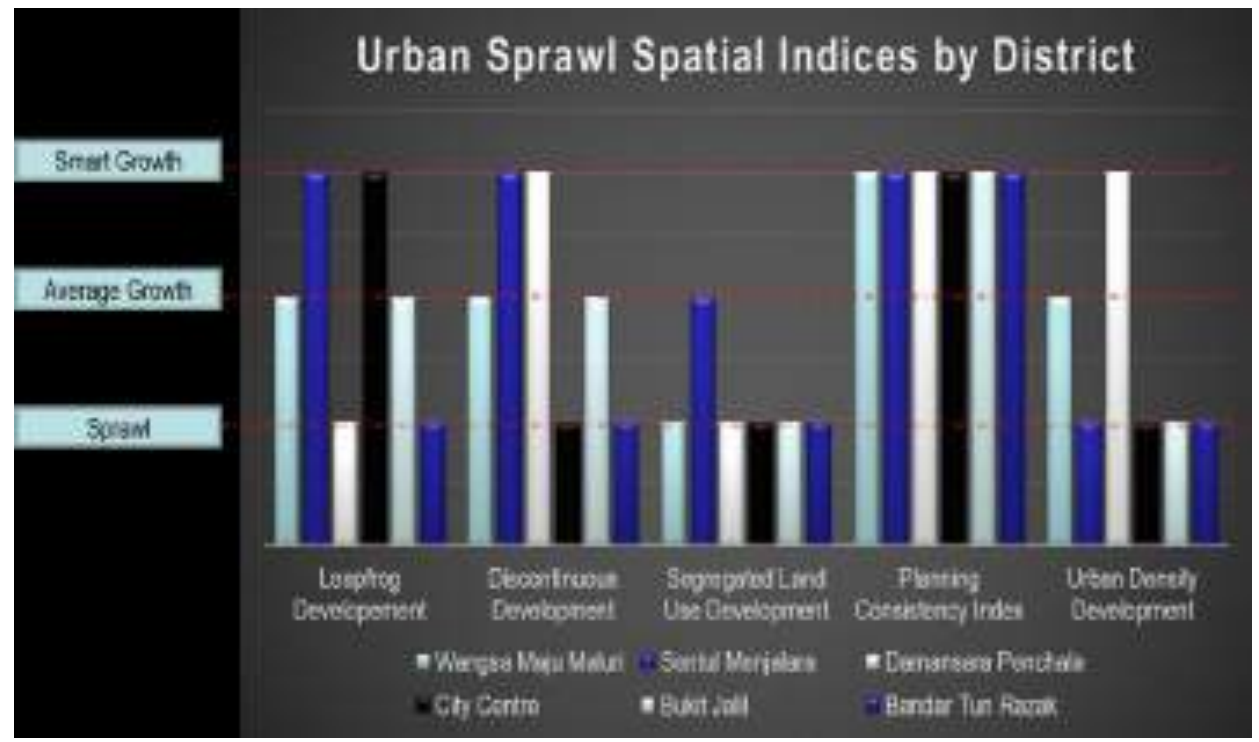

Figure 4: Urban Sprawl spatial indices by District

The finding shows the result of sprawl in various districts by using all of the land use types as its point of calculation. Figure 4 displays the result of sprawl measurement by using the residential area as the point of calculation. The residential area was chosen due to its influence on urbanisation process (demand from the population) and one of the common factors towards urban sprawl growth. Planning consistency index sprawl has the highest scores where the entire district in Kuala Lumpur scores 'smart growth'. This situation indicates that all of the residential areas that have been developed has followed the land use location and the requirement by the local authority; Kuala Lumpur City Council. At the meantime, segregated land use development and urban density development are the real sprawling problems in Kuala Lumpur. These types of sprawl occurred in the newest residential area for all district. The new residential area in Kuala Lumpur tends to be segregated and built with the low density especially residential area outside the city centre. As was previously mention, due to urbanisation factor, many choose to stay outside the city centre due to lower cost of the opportunity to have spacious living area. While for leapfrog development and discontinuous development sprawl, the score is average for all categories (each score have two districts). By looking further into these two characteristics, some suitable measures can be taken to overcome its growth in order to enhance those district that fall under average growth and sprawling. 
Nur Aulia Rosni, Norzailawati Mohd Noor \& Alias Abdullah

Managing Urbanisation and Urban Sprawl in Malaysia by Using Remote Sensing and GIS Applications

\section{CONCLUSION AND RECOMMENDATIONS}

In contrast to the rich literature on urban sprawl in Western cities, little is known about Malaysia urban sprawl growth. This paper provides a brief assessment and analysis of types of urban sprawl that occurred along with the urbanisation Kuala Lumpur. The complex nature of land use pattern in urban sprawl requires measures to employ multiple geospatial indices. In this research, we examine the most significant indicators related to five land use spatial factors using remote sensing imagery data and GIS approach. We realize the application of technology in city management is important since cities were growing rapidly in most developing countries. However, there is other possible measures or variation to the measures employed here that hold potential for spatial analysis of urbanisation in general \& urban sprawl in specific. Land use spatial patterns index provide a significant approach for identifying, comparing, and contrasting sprawl development in a more detailed manner for further investigation of the underlying process at play. As urban patterns for given region change with time, that reflected in changing sprawl index value and its technological tools may itself provide insight into the long-term patterns, underlying process, and likely consequences of spreading development compared to its smart growth analysis. Although the GIS and remote sensing application is a universal technique that being used worldwide, the geospatial indices of urban sprawl that being employed in this research are original to solve the urban sprawl problem in western cities. There will be a lot of things to be improved in the future to ensure that the geospatial indices being used to identify sprawl are suitable with urbanisation in the different geographical area as compared from its original background. It is researcher's biggest hope that the measures used in the research will be refined so in the future it will be useful for managing urban sprawl growth along with urbanisation in the cities of South East Asia. 


\section{ACKNOWLEDGEMENT}

The authors wishing to greatly acknowledge assistance from the Malaysian Remote Sensing Agency, Kuala Lumpur City Council, JUPEM, MACRES, and Town and Urban Planning Department for providing invaluable respective data used in this study. The Academy of Science Malaysia (ASM) and International Institute for Applied System Analysis (IIASA) for sponsored training and technical support. Authors sincerely thank all referees for their suggestions to improve the manuscript.

\section{REFERENCES}

Abdullah, J. (2012). City Competitiveness and Urban Sprawl: Their Implications to Socio-Economic and Cultural Life in Malaysian Cities. Procedia - Social and Behavioral Sciences, 50(July), 20-29. doi:10.1016/j.sbspro.2012.08.012

Agarwal, S., Satyavada, S., Kaushik, S. \& Kumar, R. (2007). Urbanization, Urban Poverty And Health Of The Urban Poor: Status, Challenges And The Way Forward. Demography India, 36, 1, p.p 121.

Bhatta, B., Saraswati, S., \& Bandyopadhyay, D. (2010). Quantifying the Degree-OfFreedom, Degree-Of-Sprawl, and Degree-Of-Goodness of Urban Growth from Remote Sensing Data. Applied Geography, 30(1), 96-111. doi:10.1016/j.apgeog.2009.08.001

Burchell, R. W., Shad, N. A., Listokin, D., \& Phillips, H. (1998). The Cost of Sprawl Revisited. Washington, D.C.

Ewing, R., Meakins, G., Hamidi, S., \& Nelson, A. C. (2014). Relationship Between Urban Sprawl and Physical Activity, Obesity, and Morbidity - Update and Refinement. Health and Place, 26, 118-126. doi:10.1016/j.healthplace.2013.12.008

Ewing, R., Pendall, R., \& Chen, D. (2002). Measuring Sprawl and Its Impact. Smart Growth Americar from http://www.smartgrowthamerica.org/sprawlindex/sprawlindex.html

Galster, G., Hanson, R., Ratcliffe, M. R., Wolman, H., Coleman, S., \& Freihage, J. (2001). Wrestling Sprawl to The Ground: Defining and Measuring an Elusive Concept. Housing Policy Debate, 12(4), 681-717. doi:10.1080/10511482.2001.9521426

Herold, M., Goldstein, N. C., \& Clarke, K. C. (2003). The Spatiotemporal Form of Urban Growth: Measurement, Analysis and Modeling. Remote Sensing of Environment, 86(3), 286-302. doi:10.1016/S0034-4257(03)00075-0

Herold, M., Menz, G., \& Clarke, K. C. (2001). Remote Sensing and Urban Growth Models - Demands and Perspectives. Regensburger Geographische Schriften, 35, $78 \quad-\quad 88 . \quad$ Retrieved from $\quad$ http://www.eo.unijena.de/ c5hema/pub/herold_menz_clarke.pdf

Jaafar, J. (2004). Emerging trends of urbanisation in Malaysia. Journal of the Department of Statistics, Malaysia 1(1), 43-54.

Majid, M. R., \& Yahya, H. (2010). Sprawling of a Malaysian City: What Type and What Solutions? *. The First International Conference on Sustainable Urbanization (ICSU 2010), (December), 15-17.

Mohd Noor, N., Hashim, M., \& Marghany, M. (2009). Modeling sprawl of unauthorized development using geospatial technology: Case study in Kuantan district, Malaysia. International Journal of Digital Earth. 2011;4(3):223-238. 
Nur Aulia Rosni, Norzailawati Mohd Noor \& Alias Abdullah

Managing Urbanisation and Urban Sprawl in Malaysia by Using Remote Sensing and GIS Applications

Sudhira, H. S., \& Ramachandra, T. V. (2007). Characterising Urban Sprawl from Remote Sensing Data and Using Landscape Metrics. In 10th International Conference on Computers in Urban Planning and Urban Management. Brazil.

Weng, Q. (2001). A Remote Sensing - GIS Evaluation of Urban Expansion and its Impact on Surface Temperature in The Zhujiang Delta, China. International Journal Remote Sensing, 22(10), 1999-2014.

Wilson, E. H., Hurd, J. D., Civco, D. L., Prisloe, M. P., \& Arnold, C. (2003). Development of a Geospatial Model to Quantify, Describe and Map Urban Growth. Remote Sensing of Environment, 86(3), 275-285. doi:10.1016/S0034-4257(03)00074-9

Yeh, A. G.-O., \& Li, X. (1999). An Entropy Method to Analyze Urban Sprawl in a Rapid Growing Region Using TM Images. In Asian Conference on Remote Sensing (pp. 1-6). Hong Kong. 